\title{
Team behavioral integration links team interdependence with team performance: an empirical investigation in R\&D teams
}

\author{
Xiaomeng Zhang ${ }^{1}$ and Ho Kwong Kwan ${ }^{2^{*}}$ (D)
}

\author{
* Correspondence: \\ weicheong2317@hotmail.com \\ ${ }^{2}$ School of Economics and \\ Management, Tongji University, \\ 1239 Siping Road, Shanghai 200092, \\ People's Republic of China \\ Full list of author information is \\ available at the end of the article
}

\begin{abstract}
Drawing on the input-mediator (a blend of team process and emergent state)output (IMO) framework, we develop a conceptual model in which team behavioral integration is conceived of as a team-level mediator that links team interdependence (input) with team performance (output). Using a three-wave research design, we test the hypothesized model with the data of 102 R\&D teams from three information technology companies in China. Results indicate that team interdependence positively influences team behavioral integration, and that team behavioral integration positively affects team performance. In addition, team behavioral integration is found to mediate the relationship between team interdependence and team performance. The theoretical and managerial implications of these results are discussed.
\end{abstract}

Keywords: Team interdependence, Team behavioral integration, Team performance, Top management teams, Input-mediator-outcome framework, R\&D teams

\section{Introduction}

The past decade has witnessed increasing research interest in behavioral integration among top management teams (TMTs) (Carmeli 2008; Carmeli and Halevi 2009; Carmeli and Schaubroeck 2006; Hambrick 1994, 1995, 1998, 2007; Ling et al. 2008; Lubatkin et al. 2006; Simsek et al. 2005). Behavioral integration is a meta construct that encompasses intercorrelated task and social dimensions that collectively capture the degree to which a team engages in mutual and collective interaction (Hambrick 1998; Simsek et al. 2005). In the context of TMTs, Simsek et al. (2005) have identified determinants of behavioral integration, which include characteristics of firms (e.g., size, past performance), CEOs (e.g., tenure, collective orientation), and TMTs (e.g., size, diversity). Research also shows that TMT behavioral integration results in better use of knowledge alternatives (Siegel and Hambrick 1996), improves decision quality (Carmeli and Schaubroeck 2006), and promotes corporate ambidexterity and entrepreneurship (Ling et al. 2008; Lubatkin et al. 2006), which in turn improves TMT performance (Carmeli 2008; Hambrick 1998; Mooney and Sonnenfeld 2001). Recently, using Chinese samples, research has identified that CEO empowering leadership is positively related to TMT integration, which in turn, results in an empowering organizational climate (Ou et al. 2014). Hence, the construct of behavioral integration represents "the best attempt to understand the TMT process to date" (Barrick et al. 2007: p. 545).

(c) The Author(s). 2019 Open Access This article is distributed under the terms of the Creative Commons Attribution 4.0 International License (http://creativecommons.org/licenses/by/4.0/), which permits unrestricted use, distribution, and reproduction in any medium, provided you give appropriate credit to the original author(s) and the source, provide a link to the Creative Commons license, and indicate if changes were made. 
However, to the best of our knowledge, few studies have explored behavioral integration among work teams other than TMTs. For example, using Italian R\&D teams, research has indicated that team behavioral integration is positively associated with individual improvisation (Magni et al. 2009). Additionally, results from cross-functional teams in an American university reveal that team behavioral integration positively relates to team cohesion (Tekleab et al. 2016). However, the combination of examining a team-level outcome and using $R \& D$ teams as the context is perhaps missing. The literature indicates that behavioral integration is a universal team phenomenon (Hambrick 1998; Mathieu et al. 2008), and that work teams are widely used in organizations (Campion et al. 1993). Hence, it is theoretically and practically important to extend the concept of behavioral integration from TMT settings to R\&D team settings. As the human processes and member interactions in TMTs and work teams are similar (Smith et al. 1994), it may be appropriate to transfer the construct of behavioral integration from the TMT context to the R\&D context. Moreover, as suggested by Barrick et al. (2007), constructive replication not only broadens our understanding of the concept itself but also fertilizes work team research in various theoretical streams (Cohen and Bailey 1997; O’Reilly et al. 1989).

Faced with the rapid development of a modern economy, the ability to generate and develop new products in response to changing market needs is a key to success (Subin and Workman 2004). Organizations have been dependent upon R\&D teams to achieve open innovation (e.g., Chatenier et al. 2010; Thamhain 2003; von Hippel 1988, 2005), competitiveness and sustainability (Dumaine 1994; Ilgen et al. 2005; Kim et al. 1999; Noe et al. 2000). The term R\&D team refers to the combination of two or more individuals with command of specialty technologies, who mutually coordinate to develop new products (or new manufacturing procedures) (Cohen and Bailey 1997). R\&D teams generate innovative ideas, which are then transferred through the organizational system for economic gain (Iansiti and West 1999; Thamhain 2003). However, we still know little about the critical success factors for R\&D teams (Huang 2009).

Behavioral integration is described by Hambrick (1994) as an all-encompassing meta construct that comprises three elements: collaborative behavior, quantity and quality of information exchange, and joint decision-making. R\&D team members need to collaborate while working, exchange, transfer and diffuse knowledge, and make joint decisions in order to develop new specifications and discuss technical solutions to product design problems (Chen et al. 2008). Indeed, behavioral integration among team members is essential for the functions of $R \& D$ teams as its three elements play pivotal roles in information import, processing and export, which are the main activities of $R \& D$ teams (Keller 1994). In view of the importance of behavioral integration in R\&D team settings, our extension of behavioral integration to work teams will make its first trial in R\&D team settings. Specifically, drawing on the input-mediator-outcome (IMO) framework (Gladstein 1984; McGrath 1964), a model that connects team behavioral integration with both its determinants and consequences is investigated.

One of the most important topics in team research is within-team interdependence (Barrick et al. 2007). As a team-level input (Mathieu et al. 2008), team interdependence describes the extent to which team members cooperate and work interactively to accomplish team tasks (Stewart and Barrick 2000). It consists of task, goal, and outcome interdependence (Campion et al. 1993), each of which is a key determinant of team 
effectiveness (for a review, see Gully et al. 2002). Although prominent in research on organizational teams, researchers have continued to call for empirical studies to consider team interdependence (Mathieu et al. 2008). Indeed, Kozlowski and Bell (2003) conclude that research that fails to consider team interdependence has limited value for building knowledge about organizational teams.

Although previous research has examined the effects of certain team characteristics (e.g., size, diversity) on team behavioral integration (Simsek et al. 2005), surprisingly, it has overlooked the impact of team interdependence, which is a defining team characteristic (Campion et al. 1993; Thompson 1967). We suggest that team interdependence leads to integrated behavior among team members. The underlying rationale is that interactions among team members that are task driven (task interdependence) or socially driven (goal and reward/outcome interdependence) may have a correspondingly significant impact on the task and social dimensions (e.g., the quantity and quality of information exchange and joint decision making; team collaborative behavior) of team behavior integration. The effect of team interdependence is especially salient in $R \& D$ teams, as $R \& D$ professionals have to match their own goals with the goals of their partners, be interdependent in their tasks, and share responsibility for outcomes (Chatenier et al. 2010). Hence, the first aim of this study is to build and test the theoretical connection between team interdependence and team integration behavior in the R\&D team context.

In addition to investigating the determinants of team behavioral integration, we examine its consequences. Specifically, this study examines the impact of team behavioral integration on team performance among $R \& D$ teams. Team performance is highlighted because it is one of the most important indicators of team effectiveness (Barrick et al. 2007).

Overall, this study represents an initial step toward a systematic investigation of behavioral integration among work teams, R\&D teams in particular. Drawing on the IMO framework, we aim to make five major contributions to the team interdependence and behavioral integration literature. First, we examine team interdependence as an antecedent of team behavioral integration, and thus extend the research into the links between team characteristics and team behavioral integration, which is based on traditional team demographics, by articulating a more fundamental and defining team characteristic (Campion et al. 1993). Second, we investigate the effect of team behavioral integration on team performance. Third, we explore the mediating effect of team behavioral integration on the relationship between team interdependence and team performance. An integrated model is thus presented that describes how team behavioral integration emerges and functions in R\&D teams, which answers the call from Lubatkin et al. (2006) to simultaneously examine the antecedents and consequences of team behavioral integration in a single study. Fourth, we examine this model in R\&D team contexts, and thus contribute to the research on R\&D teams. Finally, we use a three-wave research design to test the hypothesized model, where the input, mediator, and outcome variables are measured at three distinct times with four months between each time point. Research into team interdependence and behavioral integration has primarily involved cross-sectional studies of short-term project teams (Barrick et al. 2007; Gully et al. 2002). Therefore, the use of a three-wave research design to collect the data of long-standing R\&D teams (the average team age is 7.58 years), which incorporates 
the IMO framework, can greatly facilitate our understanding of the causal relationships related to team behavioral integration.

In the following section, we begin with a brief discussion of the key features of team behavioral integration and its important role in $R \& D$ team settings. We also consider the theoretical linkage between team interdependence and team behavioral integration, and between team behavioral integration and team performance in R\&D team contexts. In section 3, we introduce the method and results. We make the discussion according to the results in section 4. Finally, based on the IMO model, we conclude that team behavioral integration plays a mediating role in the relationship between team interdependence and team performance.

\section{Theoretical background and hypotheses}

Team behavioral integration in R\&D team contexts

To capture the essence of the "teamness" of TMTs, Hambrick (1994) proposes the concept of behavioral integration, which he describes as an all-encompassing meta construct that synchronizes social and task-related team processes. Team behavioral integration comprises three main elements: (a) collaborative behavior; (b) quantity and quality of information exchange (speed, accuracy, and richness); and (c) joint decision-making. Although it is a meta construct reflecting three kinds of situations, only when teams engage in these three elements simultaneously can a state of behavioral integration exist (Mathieu et al. 2008). As Lubatkin et al. (2006) suggest, a TMT's level of wholeness and unity of effort can be better captured when taking these three elements in concert than when each is examined separately. In other words, behavioral integration is a construct that yields team outputs by taking together these three mutually interrelated and reinforcing elements (Hambrick 1998; Mathieu et al. 2008).

Behaviorally integrated teams exhibit the highest degree of wholeness and unity of effort, and place great emphasis on group cohesiveness among members, who work cooperatively as real teams (Hambrick 1994, 1998). Although behavioral integration has been studied exclusively in TMTs, employing the concept of behavioral integration in TMTs to work teams is appropriate. The underlying principle is that behavioral integration is a universal team phenomenon (Hambrick 1998; Mathieu et al. 2008), and that the human processes and member interactions in TMTs and work teams are similar (Smith et al. 1994). This study therefore investigates behavioral integration in work teams, R\&D teams in particular.

According to Keller (1994), the primary activities of R\&D teams are to import scientific and technological information, then process the information into technological innovation, and finally export the innovations to another part of the organization or outside the organization. We argue that team behavioral integration is essential in information import, processing and export. Firstly, the association of collective behavior, quantity and quality of information exchange, together with joint decision-making leads to more diverse and deeper understanding of the subject matter (Lubatkin et al. 2006), which is likely to promote the import of information into $R \& D$ teams. Secondly, the degree of behavioral integration, especially the degree of collaboration and information exchange, directly influences how $R \& D$ team members deal with information processing as $R \& D$ teams 
are characterized by intensive communication (Keller 1994) and a high degree of knowledge sharing among team members (Daghfous 2004). Lastly, since behaviorally integrated teams are found to enable knowledge and insights integration (Carmeli and Halevi 2009), teams of this kind may do a better job in illustrating information that needs to be exported to other parties. The three elements of behavioral integration, joint decision-making in particular, also increases members' commitment to initiatives, through which members are stimulated to team task, such as information export (Carmeli and Schaubroeck 2006; Ling et al. 2008). Overall, behavioral integration can promote an R\&D team to cultivate its information import, processing, and export, and thus significantly impacts the functions of R\&D teams.

\section{Team interdependence and team behavioral integration}

Interdependence is defined as the extent to which team members work collectively, affect and are affected by others (Campion et al. 1993; Johnson and Johnson 1989; Stewart and Barrick 2000; Wageman 2001). There are three main components of team interdependence: task, goal, and outcome interdependence. Task interdependence refers to the extent to which a team member believes that he/she depends on others to accomplish his/her tasks (Campion et al. 1993; van der Vegt et al. 2000); goal interdependence refers to the extent to which a team member believes that his/her goals can be reached only when the goals of others are also met (Campion et al. 1993; Weldon and Weingart 1993); and outcome interdependence refers to the extent to which a team member believes that his/her expected outcomes (e.g., rewards) depend on the performance of others (Campion et al. 1993; Shea and Guzzo 1987). Although these three forms of team interdependence are conceptually distinct, they tend to be highly interrelated in practice, and thus are likely to influence jointly the degree to which team members work together and their ability to perform effectively (Campion et al. 1993; Gully et al. 2002; van der Vegt et al. 2003). Following previous studies, we examine the overall impact of team interdependence (Barrick et al. 2007; Campion et al. 1993; Gully et al. 2002).

Interdependence is an important team characteristic, which is often considered as an input variable in work group research (Mathieu et al. 2008). On the other hand, behavioral integration has been originally introduced as TMT processes and dynamics (Hambrick 1994, 1995, 1998, 2007). It is then suggested as a blended variable of team process (the means by which team members interact to accomplish tasks) and emergent state (a cognitive, motivational, and affective state of teams which is dynamic in nature and varies as a function of team context) in a team effectiveness framework (Mathieu et al. 2008).

Team interdependence may influence behavioral integration. Among teams with a high level of task interdependence, members interact with and depend on one another to accomplish tasks (Campion et al. 1993). Research indicates that cooperative behavior among team members is more likely to exist among teams with high levels of task interdependence than among those with low levels of task interdependence (Organ 1988; Ramamoorthy and Flood 2004). In order to execute interrelated tasks, mutual trust has to be developed among team members. As mutual trust is found to promote the sharing of unique information, knowledge, and resources (Houghton et al. 2000; Mohammed and Dumville 2001; Peters and Karren 2009; Ramamoorthy and Flood 
2004) as well as coordination in group decision-making (Campion et al. 1993), interrelated tasks are likely to facilitate information exchange and joint decision-making among team members conducting tasks of this kind. Hence, task interdependence is likely to play a significant role in influencing team behavioral integration.

Goal interdependence is also likely to facilitate team behavioral integration. The causal effect of goal interdependence on collaboration has been found by Wageman (1995) to be that individuals are more likely to cooperate with others when they realize that the achievement of their goals is dependent on the attainment of the goals of others. Hence, goal interdependent teams may demonstrate higher levels of collaborative behavior than their non-goal interdependent counterparts. Also, goal interdependence increases the sense of sharing a common fate among team members. To achieve collective goals, team members are likely to share their unique information, knowledge, and resources (Deutsch 1973) and make joint decisions (Barrick et al. 2007).

Outcome interdependence is also very important for team behavioral integration. Campion et al. (1993) suggest that individual feedback and rewards should be linked to group performance to motivate group-oriented behavior. The distribution of rewards according to individual performance, such as bonuses and time off, increases team conflict and decreases team cohesion (Campion et al. 1993; Miller and Hamblin 1963). In contrast, shared rewards motivate members to coordinate and cooperate with each other, and encourage an open flow of communication among team members (Gully et al. 2002). The reason is that, in order to get rewards which are based on the performance of the group as a whole, members have to increase collaboration and communication to ensure every individual in the team try his/her utmost to complete the task. Accordingly, motivated by shared rewards, members collaborate, exchange information, and make joint decisions more frequently. All of these interactions lay the foundation for behaviorally integrated teams (Hambrick 1994).

Taking the above-mentioned arguments together, it is logical to expect that team interdependence (task, goal, and outcome interdependence) will be positively associated with team behavioral integration. Such expectations may be especially sound in an $R \& D$ team context as it emphasizes the importance of bringing together team members' expertise, skills, experience and business acumen, and attaches great importance to the task and social interactions among team members (Keller 1994). Accordingly, we propose:

Hypothesis 1: Team interdependence is positively related to team behavioral integration in RED teams.

\section{Team behavioral integration and team performance}

Research shows that TMT behavioral integration is essential to firm performance (Carmeli 2008; Hambrick 1998; Lubatkin et al. 2006; Mooney and Sonnenfeld 2001). Extending the research of TMT behavioral integration to work teams, this research examines the effect of team behavioral integration on team performance in work teams, R\&D teams in particular.

Team performance requires mutual interaction and cooperation among team members, and the ultimate team goal cannot be achieved unless all team members interactively collaborate on task completion (Wageman 1995). According to Hambrick (1994), behaviorally 
integrated teams are characterized by high levels of collaboration among team members. Collaboration integrates the complementary resources, skills, experience, and knowledge of team members, enhances the collective understanding of the task, team, equipment, and situation, and thus improves team performance (Mohammed and Dumville 2001). A high level of team behavioral integration is also associated with high-quality information exchange and joint decision-making among team members (Hambrick 1994). Research shows that by pooling information and making decisions together, teams can generate more alternatives, better evaluate alternatives, and develop high-quality and synthetic solutions to solve complex problems, which in turn results in superior team performance (Carmeli 2008; Mooney and Sonnenfeld 2001; Somech et al. 2008; van der Vegt and Janssen 2003).

The positive effect of behavioral integration on team performance may be especially salient in R\&D team settings because behavioral integration significantly influences the primary activities of R\&D teams, namely information import, processing and export (Keller 1994). In line with this argument, previous studies in R\&D contexts have demonstrated the pivotal roles of collaboration (Huang et al. 2010), information exchange (Huang 2009), and joint decision-making (Zhang et al. 2007a, b) for effective team functioning and performance. Therefore, we propose:

Hypothesis 2: Behavioral integration is positively related to team performance in RED teams.

\section{The mediating role of team behavioral integration}

Based on McGrath's (1964) input-process-output (IPO) model, which is one of the most widely used models for studying team effectiveness, we develop an IMO model (Mathieu et al. 2008). Inputs are the "antecedent factors that enable and constrain members' interactions" (Mathieu et al. 2008: p. 412); mediators are the blend of team processes and emergent states (Mathieu et al. 2008); and outputs are the results and by-products of team activity. It has been well argued that team inputs indirectly affect team outcomes through team mediators (team processes and emergent states).

Applying the IMO model to our study, team interdependence can be seen as the team input (e.g., Mathieu et al. 2008; Tjosvold et al. 2004; Wageman 1995), team behavioral integration can be seen as a blend of team process and emergent state, i.e., the mediator (Mathieu et al. 2008), and team performance is the team output. As team interdependence is hypothesized to positively influence team behavioral integration, and team behavioral integration is hypothesized to be positively related to team performance. Based on the IMO model, it is logical to further propose that team behavioral integration will mediate the relationship between team interdependence and team performance. Hence, we posit:

Hypothesis 3: Behavioral integration mediates the relationship between team interdependence and team performance in R\&D teams.

\section{Methods}

\section{Sample and procedures}

We collected data from 102 R\&D teams from three information technology companies in China (company 1 is a cell phone manufacturer, company 2 is a software firm, 
and company 3 is a networking integrated system provider). IT companies rely on $R \& D$ teams to a higher degree compared to companies of other types, which provides us an ideal context to test our theoretical model. The participants were professional-level employees who were members on these teams and the corresponding external team leaders. With the assistance of the human resources managers from the three companies, a list of randomly selected 113 teams was obtained. All 866 team members (the number of team members ranges from 5 to 14 with an average of about 8) and 113 external team leaders were invited to participate in the survey. Team leaders in this study are the external leaders of these teams. They are not part of the team, as all of them supervise more than one team (ranging from two to four teams). We randomly chose one team for each team leader to prevent the design effect (Kaiser et al. 2006).

Separate questionnaires were given to team members and team leaders in person based on the list. Survey questionnaires were coded before distribution and the human resources departments assisted in recording the identification numbers to match team leaders' responses with team members' responses. Following the commonly used back translation procedure, the scales were translated from English into Chinese and then back translated into English by two independent bilingual individuals to ensure equivalency of meaning (Brislin 1980). Respondents were informed that the survey aimed to examine the experience of the human resources practices and were assured of confidentiality. Moreover, to increase response rates, gifts were provided to the participants and reminders were sent to those who did not finish the questionnaire in time. Each respondent placed his/her completed survey in a sealed envelope and dropped it into a box set up in the human resources department in each company.

Three waves of data collection from two different sources, which lasted eight months, were performed in order to reduce potential common method bias (Podsakoff et al. 2003). In the first wave, we gave questionnaires to all 866 team members, and asked them to report their own demographics and team interdependence. We dropped survey responses with the same choices without variations and received usable survey responses from 729 team members affiliated with 110 teams, with a response rate of $84.2 \%$. Four months later, in the second wave, questionnaires were distributed to the 729 team members to evaluate team behavioral integration. As 10 team members had either changed their team affiliation or left the company, only 719 team members received these questionnaires. We received usable survey responses from 628 team members affiliated with 107 teams, with a response rate of 87.3\%. After deleting those teams with less than three team members, we had 105 teams with 624 team members remaining in the wave-two sample. Finally, four months after the second-wave survey, in the third wave, questionnaires were distributed to the 105 external team leaders to rate team performance and provide information on their own demographics and team demographics. We confirmed with the human resources departments in all three companies that all teams did not change their leaders across times 1, 2, and 3. We had 102 team leaders return the questionnaires. After matching leader-team pairs and deleting eight individuals who had either changed their team affiliation or left the company during the last four months, the final sample of this study consisted of 102 teams, which included 102 team leaders and 598 team members. All participants, including team leaders and members, were affiliated with the same team across times 1,2 , and 3.

There are several reasons why we got high response rates (Baruch and Holtom 2008). First, we had personal connections with the CEOs of the three companies, which 
greatly facilitated our data collection. Second, as confidentiality was guaranteed, the employees trusted us. Third, we conducted the data collection in person and strictly monitored the whole process. Fourth, to encourage participation, gifts were provided to participants, and reminders were sent to those who did not finish the questionnaire in time. Finally, our data were collected from China. Previous research indicates that high response rates are usual in Chinese contexts (Hui et al. 2004). Hence, it is not surprising that we got relatively high response rates.

Of the 102 teams, the average team size is $7.65(\mathrm{SD}=2.07$, excluding the external team leader) and the average team age is 7.58 years $(\mathrm{SD}=2.26)$. Among the 102 external team leaders, $80.4 \%$ are men, with an average age of 36.06 years $(\mathrm{SD}=5.82)$, and all of them hold bachelor or above degrees (51.0\% held bachelor degrees and $49.0 \%$ held postgraduate degrees). Among the 598 team members, $65.1 \%$ are men, with an average age of 32.89 years $(\mathrm{SD}=4.98)$, and most of them hold bachelor or above degrees $(2.5 \%$ high school degrees, $29.1 \%$ associate degrees, $36.6 \%$ bachelor degrees, and $31.8 \%$ postgraduate degrees).

\section{Measures}

\section{Team interdependence}

We use Campion et al.'s (1993) nine-item scale to measure team interdependence, and each dimension (task, goal, and outcome interdependence) is measured by three items. Response options range from 1, "strongly disagree," to 5, "strongly agree." Sample items include: "Within the team, jobs performed by team members are related to one another (task interdependence)," "My work goals come directly from the goals of our team (goal interdependence)," and "My performance evaluation is strongly influenced by how well my team performs (outcome interdependence)." We conduct a confirmatory factor analysis (CFA) to assess the psychometric characteristics of the measure. The fit indices for three first-order factors plus one second-order factor fall within an acceptable range $\left(\chi^{2}\right.$ $(24)=87.20, p \leq 0.01$; RMSEA $=0.066 ; \mathrm{CFI}=0.98 ; \mathrm{TLI}=0.97)$. Cronbach's alpha is 0.83 for task interdependence, 0.87 for goal interdependence, 0.80 for outcome dependence, and 0.92 for the whole scale.

\section{Team behavioral integration}

We use Simsek and collegues' (2005) nine-item scale to measure team behavioral integration, and each dimension (collaborative behavior, information exchange and joint decision making) is measured by three items. Response options range from 1, "strongly disagree," to 5, "strongly agree." Sample items include: "When a team member is busy, other team members often volunteer to help manage the workload" (collaborative behavior), "Our team is effective in developing high-quality ideas" (information exchange), and "Team members have a clear understanding of the joint problems and needs of other team members" (joint decision making). We conduct a CFA to assess the psychometric characteristics of the measure. The fit indexes for three first-order factors plus one second-order factor fall within a good range $\left(\chi^{2}(24)=102.14, p \leq 0.01\right.$; RMSEA = 0.074; CFI $=0.97$; TLI $=0.96$ ). Cronbach's alpha is 0.83 for collaborative behavior, 0.84 for information exchange, 0.81 for joint decision making, and 0.91 for the whole scale. 


\section{Team performance}

We use Zellmer-Bruhn and Gibson's (2006) five-item scale to measure team performance. Response options range from 1 , "strongly disagree," to 5 , "strongly agree." A sample item is: "This team achieves its goals." Cronbach's alpha of this scale is 0.82 .

\section{Control variables}

Based on previous studies (e.g., Kearney et al. 2009; Simsek et al. 2005; Zhang et al. 2007a, b), we control for several key variables that are likely to be associated with team behavioral integration and team performance. First, team size (the number of members in a team) and team age (years since the team formed) are controlled. Second, team age diversity and team gender diversity are controlled. Following Allison (1978) and Cannella et al. (2008), we calculate team age diversity using the coefficient of its variation (its superlative standard deviation divided by its mean). Since gender is a categorical variable, following Shin and Zhou (2007), we measure team gender diversity using Blau's (1977) index of heterogeneity calculated as $1-\sum S i^{2}$, where $S i$ is the portion of a team's members in the $i$ th category. Third, as our sample was taken from three companies, we creat two company dummies and add them as control variables in the structural equation model to rule out the potential company effect.

\section{Preliminary analyses}

Attrition analysis

Since two waves of data were collected from team members, we follow Goodman and Blum's (1996) approach to test whether there are systematic response differences between the first and the second wave of data collection. First, a multiple logistic regression is conducted using survey time as the dependent variable and team member age, gender and education level, and team interdependence as the independent variables. Results show that all logistic regression coefficients are insignificant. Moreover, $t$-tests are performed to assess whether there are significant mean differences in team member age, gender and education level, and team interdependence across time 1 and time 2. Results indicate no significant mean difference for these variables. Taken together, the above results suggest that the team members randomly dropped out from the study.

\section{Level of analysis and data aggregation}

To justify the aggregation of individual responses to team measures, we calculate inter-team-member agreement $\left(r_{w g}\right)$ and intra-class correlation coefficients ICC ${ }_{(1)}$ and ICC $_{(2)}$ (Bliese 2000; James 1982; James et al. 1984). The results of the aggregation are detailed in Table 1.

As shown in Table 1, the percentage of teams with $r_{w g}(\mathrm{j})$ values of 0.70 and above on all scales range from $97.1 \%$ (e.g., joint decision making) to $100 \%$ (e.g., team interdependence). The levels of inter-member agreements within teams thus justify our aggregation of individual-level data (James et al. 1984). In addition, results show that ICC (1) values of all variables range from 0.13 (goal interdependence) to 0.27 (team behavioral integration), which are greater than the conventional cut-off values of 0.05 . Furthermore, ICC ${ }_{(1)}$ values of all variables are significant, indicating that between-team variances are larger than within-team variances. Finally, ICC (2) values of all variables range from 0.47 (goal 
Table 1 Information for justifying aggregation of individual measurements to the team level

\begin{tabular}{|c|c|c|c|c|c|c|c|c|}
\hline & \multirow{2}{*}{$\begin{array}{l}\text { Variance } \\
\text { analysis } \\
\text { across } \\
\text { teams } \\
\text { (ANOVA } \\
\text { test) }\end{array}$} & \multirow[t]{2}{*}{$I C C_{(1)}$} & \multirow[t]{2}{*}{$\operatorname{ICC}(2)$} & \multicolumn{5}{|l|}{$r_{w g}$} \\
\hline & & & & Median & Minimum & Maximum & $\begin{array}{l}\text { Number of } \\
\text { teams below } \\
0.70\end{array}$ & $\begin{array}{l}\text { Percentage of } \\
\text { total teams } \\
\text { above } 0.70\end{array}$ \\
\hline $\begin{array}{l}\text { Team } \\
\text { interdependence }\end{array}$ & Significant $^{a}$ & 0.25 & 0.66 & 0.95 & 0.83 & 1.00 & 0 & $100 \%$ \\
\hline $\begin{array}{l}\text { Task } \\
\text { interdependence }\end{array}$ & Significant & 0.17 & 0.54 & 0.92 & 0.75 & 1.00 & 0 & $100 \%$ \\
\hline $\begin{array}{l}\text { Goal } \\
\text { interdependence }\end{array}$ & Significant & 0.13 & 0.47 & 0.91 & 0.59 & 1.00 & 3 & $97.1 \%$ \\
\hline $\begin{array}{l}\text { Outcome } \\
\text { interdependence }\end{array}$ & Significant & 0.15 & 0.50 & 0.92 & 0.69 & 1.00 & 1 & $99 \%$ \\
\hline $\begin{array}{l}\text { Team behavioral } \\
\text { integration }\end{array}$ & Significant & 0.26 & 0.67 & 0.95 & 0.81 & 0.99 & 0 & $100 \%$ \\
\hline $\begin{array}{l}\text { Collaborative } \\
\text { behavior }\end{array}$ & Significant & 0.15 & 0.51 & 0.91 & 0.48 & 0.99 & 1 & $99 \%$ \\
\hline $\begin{array}{l}\text { Information } \\
\text { exchange }\end{array}$ & Significant & 0.16 & 0.53 & 0.92 & 0.55 & 0.99 & 1 & $99 \%$ \\
\hline $\begin{array}{l}\text { Joint decision } \\
\text { making }\end{array}$ & Significant & 0.15 & 0.51 & 0.92 & 0.51 & 0.99 & 3 & $97.1 \%$ \\
\hline
\end{tabular}

Notes. $N=102$; "significant" means that "between-team variance" is significantly larger than "within-team variance"

interdependence) to 0.67 (behavioral integration), relatively low values that may limit the power to detect significant team relationships. In sum, the above results indicate that it was appropriate to average the scores provided by team members to obtain the team-level scores.

\section{Confirmatory factor analyses}

Confirmatory factor analyses are conducted to examine the validity of the key variables with AMOS 19.0. Given the small sample size relative to the measurement items, we follow previous studies and reduce the number of indicators for the research constructs by creating three indicators for each latent variable. Each indicator is represented by the dimension score (Hau and Marsh 2004).

We first test a three-factor model in which team interdependence, team behavioral integration, and team performance are included. CFA results indicate that the three-factor model fit the data very well: $\chi^{2}(24)=51.51, p \leq 0.01$; RMSEA $=0.050$; CFI $=0.98$; TLI $=$ 0.99 . In addition, all the factor loadings are significant.

The distinctness of the three constructs is then tested by contrasting the three-factor model against a two-factor and a one-factor model. We combine team behavioral integration and team performance to form the two-factor model because their association is the highest among the three constructs. The one-factor model is obtained via loading all measuring items into a "grand" latent factor. The two-factor and one-factor models yield much poorer fits to the data: $\chi^{2}(26)=172.43, p \leq 0.01$; RMSEA $=0.173$; CFI $=0.83$; TLI $=0.78$ for the two-factor model and $\chi^{2}(27)=429.34, p \leq 0.01$; RMSEA $=0.294$; CFI $=0.48$; TLI $=0.35$ for the one-factor model. A Chi-square difference test indicates that the hypothesized three-factor model fit the data better than the two-factor model $\left(\Delta \chi^{2}(2)=120.92, p \leq 0.01\right)$ and the one-factor model $\left(\Delta \chi^{2}(3)=377.83, p \leq 0.01\right)$. 


\section{Descriptive statistics}

Table 2 presents the means, standard deviations, zero-order Pearson correlations, and scale reliabilities for all key variables in the main study. As shown in Table 2, team interdependence is positively correlated with team behavioral integration $(r=0.38, p \leq$ $0.01)$ and team performance $(r=0.22, p \leq 0.05)$. Moreover, team behavioral integration is positively correlated with team performance $(r=0.44, p \leq 0.01)$.

\section{Hypotheses testing}

The positive correlation between team interdependence and team behavioral integration $(r=0.38, p \leq 0.01)$ provides preliminary support for Hypothesis 1 . In addition, team behavioral integration is found to be positive correlated with team performance ( $r=$ $0.22, p \leq 0.05$ ), thus also providing initial support for Hypothesis 2 .

We use nested model comparisons to test Hypothesis 3, which states that team behavioral integration mediates the relationship between team interdependence and team performance. Table 3 presents the results.

Model 1 is our mediation model. Besides the direct paths from the controlled variables to team behavioral integration and team performance, we specify the path from team interdependence to team behavioral integration, and the path from team behavioral integration to team performance. The direct path from team interdependence to team performance is not specified. As shown in Table 1, Model 1 fits the data very well: $\chi^{2}(73)=118.97, p \leq 0.01$; RMSEA $=0.056$; CFI $=0.97$; TLI $=0.95$.

Model 1 is tested against an alternative nested model (partial-mediation model). Specifically, based on Model 1, we add a direct path from team independence to team performance to form Model 2. Results show that Model 2 also yields a good fit to the data: $\chi^{2}(72)=117.38, p \leq 0.01$; RMSEA $=0.056$; CFI $=0.97$; TLI $=0.95$. However, results from the nested model comparisons show that the difference between Chi-squares are not significant for Model 1 compared with Model 2. Hence, based on the principle of model parsimony, we conclude that Model 1 best fits our data. The path from team interdependence to team performance is not significant $(\beta=0.09)$. Hence, Hypothesis 3 ,

Table 2 Means, standard deviations, and correlations

\begin{tabular}{lllllllllllll}
\hline Variable & Mean & SD & 1 & 2 & 3 & 4 & 5 & 6 & 7 & 8 & 9 & 10 \\
\hline Age diversity & 0.14 & 0.05 & & & & & & & & & \\
Gender diversity & 0.39 & 0.13 & 0.13 & & & & & & & & \\
Team size & 7.65 & 2.07 & 0.07 & $0.30^{* *}$ & & & & & & & \\
Team age & 7.58 & 2.26 & -0.19 & -0.14 & -0.14 & & & & & & \\
Company 1 & 0.37 & 0.49 & -0.08 & -0.17 & -0.14 & 0.13 & & & & & \\
Company 2 & 0.42 & 0.50 & 0.13 & $0.26^{* *}$ & $0.34^{* *}$ & $-0.25^{*}$ & $-0.66^{* *}$ & & & & \\
Company 3 & 0.21 & 0.41 & -0.07 & -0.12 & $-0.24^{*}$ & 0.15 & $-0.39^{* *}$ & $-0.44^{* *}$ & & & \\
Team & 4.58 & 0.67 & -0.11 & - & 0.02 & -0.02 & 0.10 & -0.06 & -0.04 & $(0.92)$ & \\
interdependence & & & & 0.03 & & & & & & & \\
Team behavioral & 4.66 & 0.63 & -0.03 & 0.15 & 0.02 & 0.09 & 0.03 & 0.04 & -0.08 & $0.38^{* *}$ & $(0.91)$ \\
integration & & & & & & & & & & & \\
Team performance & 4.62 & 0.76 & 0.00 & 0.03 & -0.09 & $0.30^{* *}$ & -0.05 & -0.06 & 0.13 & $0.22^{*}$ & $0.44^{* *}$ & $(0.82)$ \\
\hline
\end{tabular}

Notes. $N=102 ;{ }^{* *} p \leq 0.01 ;{ }^{*} p \leq 0.05$ (two-tailed)

Bracketed values on the diagonal are the Cronbach's alpha value of each scale 
Table 3 Comparison of structural equation models

\begin{tabular}{lllllll}
\hline Model and structure & $x^{2}$ & $d f$ & $\Delta x^{2}$ & CFI & TLI & RMSEA \\
\hline M1. TI $\rightarrow$ TBI $\rightarrow$ Team performance & 118.97 & 73 & & 0.97 & 0.95 & 0.056 \\
M2. TI $\rightarrow$ TBI $\rightarrow$ Team performance & 117.38 & 72 & 1.59 & 0.97 & 0.95 & 0.056 \\
$\begin{array}{l}\text { and TI } \rightarrow \text { Team performance } \\
\text { M3. TI }+ \text { TBI } \rightarrow \text { Team performance }\end{array}$ & 134.38 & 73 & 15.41 & 0.95 & 0.92 & 0.070 \\
\hline
\end{tabular}

Notes. $N=102 ;{ }^{* *} p \leq 0.01 ;{ }^{*} p \leq 0.05$ (two-tailed)

$\mathrm{TI}=$ team interdependence; $\mathrm{TBI}=$ team behavioral integration

* baseline model for comparison

which predicts that team behavioral integration mediates the relationship between team interdependence and team performance, is supported.

Model 3 is an alternative model that is not nested within the above two models. We include Model 3 because we want to rule out the possibility that both team interdependence and team behavioral integration directly influence team performance. Results show that Model 3 also yields a good fit to the data: $\chi^{2}(73)=134.38, p \leq 0.01$; RMSEA $=0.070$; CFI $=0.95$; TLI $=0.92$. However, the path from team interdependence to team performance is not significant $(\beta=0.10)$. Moreover, the Chi-square difference test indicates that Model 1 fits the data much better than Model $3\left(\Delta \chi^{2}=15.41, p \leq\right.$ 0.01). Hence, Hypothesis 3 receives further support.

Moreover, we apply bootstrapping analyses to examine the mediating effect with 10,000 replications. Because the $95 \%$ confidence interval excludes zero (effect $=0.18$, $\mathrm{SE}=0.06, p \leq 0.01,95 \%$ confidence interval $[0.07,0.33])$, the bootstrapping results further support Hypothesis 3.

Figure 1 presents the results of our hypotheses testing (Model 1). As shown in Fig. 1, team interdependence is positively related to team behavioral integration $(\beta=0.41, p \leq$

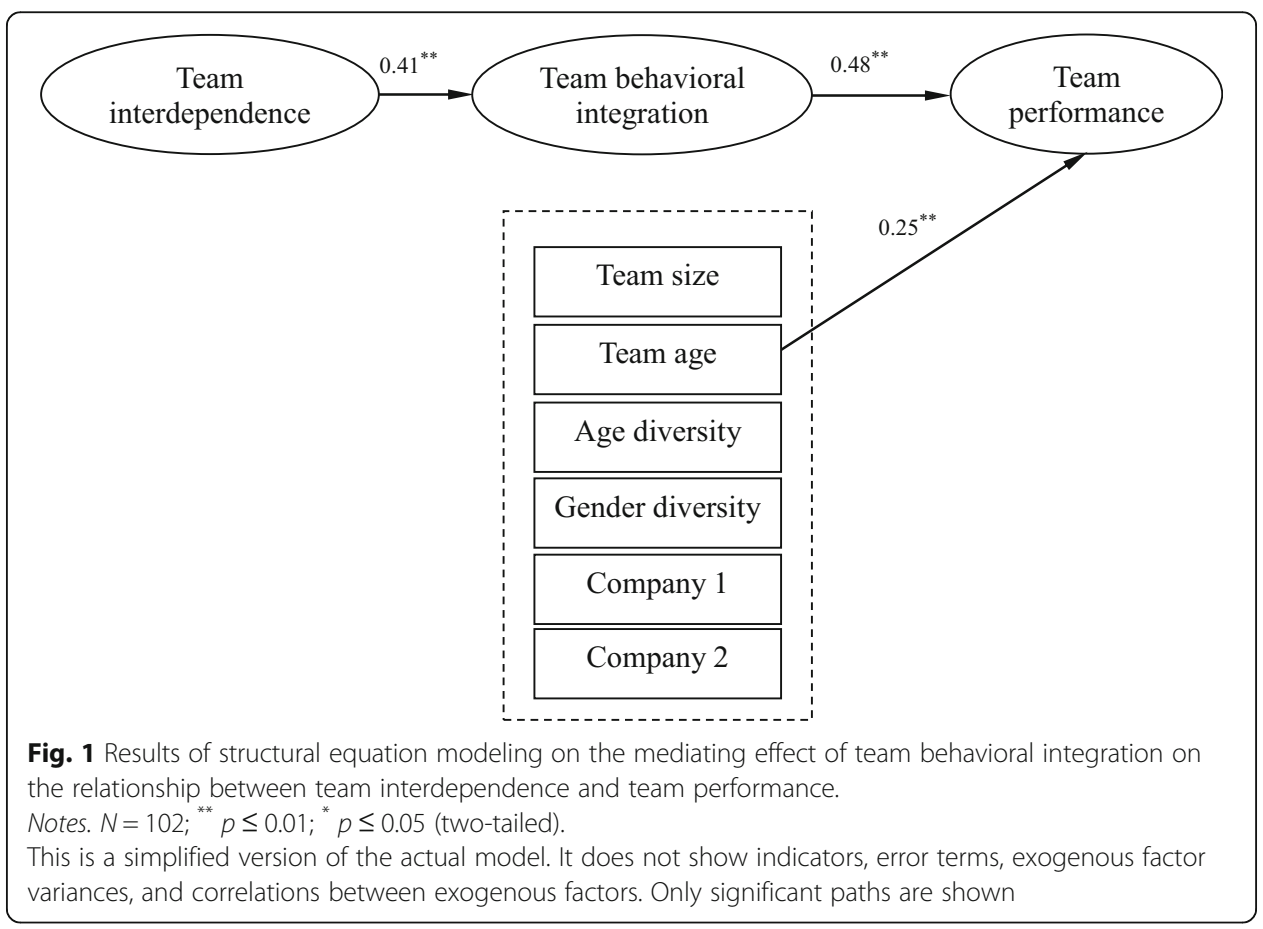


0.01), supporting Hypothesis 1 . In addition, in support of Hypothesis 2 , we find that team behavioral integration is positively related to team performance $(\beta=0.48, p \leq 0.05)$.

\section{Discussion}

We hypothesize and find that team interdependence positively influences team behavioral integration, and that team behavioral integration positively affects team performance in $R \& D$ teams. In addition, the results of structure equation modeling indicate that team behavioral integration mediates the relationship between team interdependence and team performance. The theoretical and managerial implications of these findings are discussed below.

\section{Theoretical implications}

Our study makes several distinct contributions. First, it is among the first to investigate team behavioral integration in work team settings (i.e., R\&D team settings). In contrast to previous work team research, which utilizes either social or task-related processes as constructs to conceptualize team dynamics, this study models team dynamics using team behavioral integration, which is a blended construct that incorporates both social- and task-related components (Hambrick 1998; Mathieu et al. 2008). As well, contributing to team behavioral integration research, which mainly considers TMTs (Carmeli and Halevi 2009; Carmeli and Schaubroeck 2006; Ling et al. 2008; Lubatkin et al. 2006; Simsek et al. 2005), our research extends the theory of team behavioral integration from TMTs to other work teams by investigating team behavioral integration among $102 \mathrm{R} \& \mathrm{D}$ teams across three information technology companies.

Second, our study advances the research into the antecedents of team behavioral integration. Although previous research has examined the effects of some team characteristics (e.g., size, diversity) on team behavioral integration (Simsek et al. 2005), it has overlooked the impact of team interdependence, which is a defining team characteristic (Campion et al. 1993; Thompson 1967). Filling this gap, our research provides conceptual arguments for and empirical evidence of the relationship between team interdependence and team behavioral integration. Moreover, when team size, age, diversity, and interdependence are used to predict team behavioral integration, our results show that only team interdependence is significantly related to team behavioral integration. Thus, it is very likely that in R\&D team settings, team interdependence is a better predictor of team behavioral integration than team demographics. Future research should thus place attention on psychometric measurements rather than demographic variables to predict team integration behavior.

Third, although studies have established that TMT behavioral integration is associated with firm-level outcomes (e.g., firm performance, firm entrepreneurship, quality of strategic decisions, and organizational decline), understanding of the impact of behavioral integration on team-level outcomes among work teams remains limited. This research represents the first attempt to conceptualize and test the connection between team behavioral integration and team performance in $R \& D$ team settings. Our results suggest that team behavioral integration is critical for R\&D teams to achieve superior team performance. These important findings thus extend the research into the consequences of team behavioral integration by identifying a critical team-level outcome, and in so doing deepen the understanding of the influence of team behavioral integration on team effectiveness. 
Fourth, our results indicate that team behavioral integration mediates the relationship between team interdependence and team performance. This finding not only provides empirical support for the IMO model of team dynamics (Gladstein 1984; McGrath 1964), but also offers a new look at how team interdependence affects team effectiveness-through improving team behavioral integration.

Finally, the contributions of this research are further strengthened by our research design. Firstly, we employ a three-wave data collection procedure, in which data on team interdependence, team behavioral integration, and team performance are collected at three distinct time points. Such a design, in contrast to a cross-sectional one, helps to demonstrate the causal nature of the model (Cook and Campbell 1979). Second, key variables are collected either at different times or from different sources, which largely reduces the threat of common method bias (Podsakoff et al. 2003). Finally, we collect data from 102 R\&D teams across three information technology companies, which increases the observed variability and generalizability of our findings.

\section{Practical implications}

Our theoretical model and empirical findings also have important practical implications. The $R \& D$ team is increasingly important for organizations, as it generates creative work on a systematic basis, increases the stock of knowledge, and the use of this stock of knowledge to devise new applications. Our results show that team behavioral integration is beneficial for R\&D teams. On the one hand, the three elements of behavioral integration, i.e., collaboration, information exchange, and joint decision-making, are pivotal for information import, process, and export in $R \& D$ teams. On the other hand, R\&D teams with high levels of behavioral integration are likely to demonstrate better performance than those with low levels of behavioral integration. The present study indicates that by building behavioural integration among team members, R\&D teams are likely to enjoy a behavioral arsenal that enables them to perform better. Hence, R\&D team leaders should encourage team members to communicate and interact with each other so that their teams can achieve high levels of behavioral integration.

We also find that team interdependence positively influences R\&D team performance. Therefore, $R \& D$ team leaders should put more efforts into improving the team task design (e.g., job design in which the tasks of each team member are interrelated), goal structure (e.g., the establishment of common goals), and feedback and reward systems (e.g., the assignment of rewards based on team performance) to encourage high levels of task, goal, and outcome interdependence within their teams.

Finally, we find that team interdependence facilitates the development of team behavioral integration in R\&D teams. Practitioners need to align the task and social driven interactions among R\&D team members with their integrated behavior. As mentioned above, teams can increase behavioral integration through efforts to improve team interdependence. However, for those R\&D teams in which task design is fixed and hard to change, organizations should find other means to improve team behavioral integration and performance. Recent research suggests that transformational leadership is beneficial for team behavioral integration (Ling et al. 2008). Given that several aspects of leadership behavior can be learned or adjusted (Kirkbride 2006), organizations thus can provide more training and mentoring for R\&D team leaders to help them develop and display transformational leadership. 


\section{Limitations and future research directions}

This research has some limitations. First, although we collect the data from two sources, the data may still be susceptible to common method variance as we ask team members to report on team interdependence and team behavioral integration (Podsakoff et al. 2003). However, the three-wave research design and the construct validity tests indicate that common method bias is not likely to explain our findings.

Second, our data are collected from 102 R\&D teams in three Chinese information technology companies. Although this approach has the advantage of holding team type, industry and country factors constant, researchers should replicate our findings using other team categories, industries, and countries to confirm the generalizability of our findings.

Third, we do not have the data of team rotation in our data set. Theoretically, in R\&D team settings, team rotation is likely to impact team behavioral integration and performance. Specifically, low team rotation may positively influence team behavioral integration, while high team rotation could make behavioral integration more difficult. Moreover, medium levels of team rotation may be the best for team performance as teams with very low rotation may be less innovative, while those with very high rotation may be unable to develop their abilities to perform. Hence, we encourage future studies to explore how team rotation influences team behavioral integration and performance in R\&D team settings, and control for team rotation when examining team behavioral integration and performance in $R \& D$ team settings.

Fourth, in this study, the three types of interdependence (task, goal, and outcome) are combined into a composite score called team interdependence. It would be interesting to examine, for example, whether these three types of interdependence will have differential effects on behavioral integration under different conditions (e.g., different organizational cultures). Future research could do so to extend our model.

Finally, only team interdependence is studied as the antecedent of team behavioral integration, which leads to relatively less explanatory power of the model. Although team interdependence is one of the most important topics in team research (Barrick et al. 2007), and is argued to have great value for knowledge-building in work teams (Kozlowski and Bell 2003), other factors such as team leadership, team member personality traits, and team member interpersonal skills may also contribute to team behavioral integration and ultimately promote team performance in work team settings (e.g., Lessem and Baruch 2000; Ling et al. 2008; Hunt and Baruch 2003). Attention should be paid to other causal factors in future studies.

There are other areas for future research in addition to those discussed above. Researchers have identified the effects of different types of team inputs (e.g., transformational leadership, team composition) on team behavioral integration (Ling et al. 2008; Simsek et al. 2005). However, few of them have examined the joint effects of different types of team inputs on team behavioral integration. Future research should explore this topic in both TMTs and other work team settings, to advance our knowledge of how team behavioral integration develops. Furthermore, existing research into the consequences of team behavioral integration focuses on performance outcomes. As team attitudes, such as team commitment and team satisfaction, represent another important category of team outcomes (Kirkman and Rosen 1999), we encourage future research to examine the links between team behavioral integration and different team attitudes in various team settings to better understand the impact of team behavioral integration. 


\section{Conclusion}

Although behavioral integration has been widely studied in TMTs, it does not receive attention in work team settings. The present study is designed to address a number of crucial issues regarding the role of team behavioral integration in work teams, R\&D teams in particular. The study of team behavioral integration in $R \& D$ team settings is appropriate, because behavioral integration is a universal team phenomenon (Hambrick 1998; Mathieu et al. 2008), and the human processes and member interactions in TMTs and work teams are similar (Smith et al. 1994). Moreover, construct replication in different team settings may not only broaden our understanding of the concept itself but also fertilize team research in various theoretical streams (Barrick et al. 2007). The study of team behavioral integration in R\&D team settings is also important, because behavioral integration among team members is essential for the functions of an $R \& D$ team as the three elements of behavioral integration play pivotal roles in information import, process and export, which are the primary activities of R\&D teams (Keller 1994). Drawing upon the IMO framework, this study builds and tests a model in which team behavioral integration connects team interdependence with team performance. Results from a three-wave research design of 102 R\&D teams in three Chinese IT companies reveal that team interdependence positively influences team behavioral integration, which in turn leads to high levels of team performance. We hope that our research will stimulate future research to advance the theoretical understanding of how team behavioral integration emerges and influences team outcomes among work teams.

Acknowledgements

Not applicable.

Funding

Not applicable.

Availability of data and materials

Data will not be shared publicly because IRB does not allow it. Please contact the authors for data requests.

Authors' contributions

All authors contributed significantly to the manuscript. They designed the research and wrote the paper. All authors have approved the manuscript for publication.

Competing interests

The authors declare that they have no competing interests.

\section{Publisher's Note}

Springer Nature remains neutral with regard to jurisdictional claims in published maps and institutional affiliations.

Author details

${ }^{1}$ Cheung Kong Graduate School of Business, Beijing, China. ${ }^{2}$ School of Economics and Management, Tongji University, 1239 Siping Road, Shanghai 200092, People's Republic of China.

Received: 16 October 2018 Accepted: 15 March 2019

Published online: 22 April 2019

\section{References}

Allison, P. D. (1978). Measures of inequality. American Sociological Review, 43, 865-880.

Barrick, M. R., Bradley, B. H., Kristof-Brown, A. L., \& Colbert, A. E. (2007). The moderating role of top management team interdependence: Implications for real teams and working groups. Academy of Management Journal, 50, 544-557.

Baruch, Y., \& Holtom, B. C. (2008). Survey response rate levels and trends in organizational research. Human Relations, 61, $1139-1160$.

Blau, P. M. (1977). Inequality and heterogeneity. New York: Free Press.

Bliese, P. (2000). Within-group agreement, non-independence, and reliability. In K. Klein \& S. Kozlowski (Eds.), Multi-level theory, research, and methods in organizations (pp. 349-381). San Francisco: Jossey-Bass.

Brislin, R. W. (1980). Translation and content analysis of oral and written material. In H. C. Triandis \& J. W. Berry (Eds.), Handbook of cross-cultural psychology (pp. 389-444). Boston: Allyn and Bacon. 
Campion, M. A., Medsker, G. J., \& Higgs, A. C. (1993). Relations between work group characteristics and effectiveness: Implications for designing effective work groups. Personnel Psychology, 46, 823-850.

Cannella, A. A., Park, J., \& Lee, H. (2008). Top management team functional background diversity and firm performance: Examining the roles of team member co-location and environmental uncertainty. Academy of Management Journal, 51, 768-784.

Carmeli, A. (2008). Top management team behavioral integration and the performance of service organizations. Group and Organization Management, 33, 712-735.

Carmeli, A., \& Halevi, M. Y. (2009). How top management team behavioral integration and behavioral complexity enable organizational ambidexterity: The moderating role of contextual ambidexterity. The Leadership Quarterly, 20, 207-218.

Carmeli, A., \& Schaubroeck, J. (2006). Top management team behavioral integration, decision quality, and organizational decline. The Leadership Quarterly, 17, 441-453.

Chatenier, E. D., Verstegen, J. A. A. M., Biemans, H. J. A., Mulder, M., \& Omta, O. S. W. F. (2010). Identification of competencies for professionals in open innovation teams. R\&D Management, 40, 271-280.

Chen, M. H., Chang, Y. C., \& Hung, S. C. (2008). Social capital and creativity in R\&D project teams. R\&D Management, 38, 21-34.

Cohen, S. G., \& Bailey, D. E. (1997). What makes teams work: Group effectiveness research from the shop floor to the executive suite. Journal of Management, 23, 239-290.

Cook, T. D., \& Campbell, D. T. (1979). Quasi-experimentation: Design and analysis for field settings. Chicago: Rand McNally.

Daghfous, A. (2004). Absorptive capacity and the implementation of knowledge-intensive best practices. SAM Advanced Management Journal, 69, 21-27.

Deutsch, M. (1973). The resolution of conflict. New Haven: Yale University Press.

Dumaine, B. (1994). The trouble with teams. Fortune, 130(5), 86-92.

Gladstein, D. L. (1984). Groups in context: A model of task group effectiveness. Administrative Science Quarterly, 29, 499-517.

Goodman, J. S., \& Blum, T. C. (1996). Assessing the non-random sampling effects of subject attrition in longitudinal research. Journal of Management, 22, 627-652.

Gully, S. M., Beaubien, J. M., Incalcaterra, K. A., \& Joshi, A. (2002). A meta-analysis of team-efficacy, potency and performance: Interdependence and level of analysis as moderators of observed relationships. Journal of Applied Psychology, 87, 819-832.

Hambrick, D. C. (1994). Top management groups: A conceptual integration and reconsideration of the "team" label. In B. M. Staw \& L. L. Cummings (Eds.), Research in organizational behavior (pp. 171-214). Greenwich: JAl Press.

Hambrick, D. C. (1995). Fragmentation and the other problems CEOs have with their top management teams. California Management Review, 37, 110-128.

Hambrick, D. C. (1998). Corporate coherence and the top management team. In D. C. Hambrick, D. A. Nadler, \& M. L. Tushman (Eds.), Navigating change: How CEOS, top teams, and boards steer transformation (pp. 123-140). Boston, MA: Harvard Business School Press.

Hambrick, D. C. (2007). The field of management's devotion to theory: Too much of a good thing? Academy of Management Journal, 50, 1346-1352.

Hau, K. T., \& Marsh, H. W. (2004). The use of item parcels in structural equation modeling: Nonnormal data and small sample sizes. British Journal of Mathematical and Statistical Psychology, 57, 327-351.

Houghton, S. M., Simon, M., \& Goldberg, C. B. (2000). No safety in numbers: Persistence of biases and their effects on team risk perception and team decision making. Group and Organization Management, 25, 325-353.

Huang, C. (2009). Knowledge sharing and group cohesiveness on performance: An empirical study of technology R\&D teams in Taiwan. Technovation, 29, 786-797.

Huang, M., Contractor, N., Huang, Y., Margolin, D., Ognyanova, K., \& Shen, C. (2010). The effects of diversity and repeat collaboration on team performance in distributed nonscientist teams. Montreal: Paper presented in the Academy of Management Meeting.

Hui, C., Lee, C., \& Rousseau, D. M. (2004). Employment relationships in China: Do workers relate to the organization or to people. Organization Science, 15, 232-240.

Hunt, J. W., \& Baruch, Y. (2003). Developing top managers: The impact of interpersonal skills training. Journal of Management Development, 22, 729-752.

lansiti, M., \& West, J. (1999). Technology integration: Turning great research into great products. In M. lansiti, J. West, H. Chedbrough, \& D. J. Teece (Eds.), Harvard business review on managing high-tech industries (pp. 1-29). Boston: Harvard Business School Press.

Ilgen, D. R., Hollenceck, J. R., Johnson, M., \& Jundt, D. (2005). Teams in organizations: From input-process-output models to IMOI models. Annual Review of Psychology, 56, 517-543.

James, L. R. (1982). Aggregation bias in estimates of perceptual agreement. Journal of Applied Psychology, 67, 219-229.

James, L. R., Demaree, R. G., \& Wolf, G. (1984). Estimating within-group interrater reliability with and without response bias. Journal of Applied Psychology, 69, 85-98.

Johnson, D. W., \& Johnson, R. T. (1989). Cooperation and competition: Theory and research. Edina: Interaction Book Company.

Kaiser, R., Woodruff, B. A., Bilukha, O., Spiegel, P. B., \& Salama, P. (2006). Using design effects from previous cluster surveys to guide sample size calculation in emergency settings. Disasters, 30, 199-211.

Kearney, E., Gebert, D., \& Voelpel, S. C. (2009). When and how diversity benefits teams: The importance of team members' need for cognition. Academy of Management Journal, 52, 581-598.

Keller, R. T. (1994). Technology-information processing fit and the performance of R\&D project groups: A test of contingency theory. Academy of Management Journal, 37, 167-179.

Kim, Y., Min, B., \& Cha, J. (1999). The roles of R\&D team leaders in Korea: A contingent approach. R\&D Management, 29, 153-165.

Kirkbride, P. (2006). Developing transformational leaders: The full range leadership model in action. Industrial and Commercial Training, 38, 23-32.

Kirkman, B. L., \& Rosen, B. (1999). Beyond self-management: Antecedents and consequences of team empowerment. Academy of Management Journal, 42, 58-74.

Kozlowski, S. W. J., \& Bell, B. S. (2003). Work groups and teams in organizations. In W. C. Borman, D. R. Ilgen, \& R. J. Klimoski (Eds.), Handbook of psychology: Industrial and organizational psychology (pp. 333-375). Hoboken: John Wiley and Sons.

Lessem, R., \& Baruch, Y. (2000). Testing the SMT and Belbin inventories in top management teams. Leadership and Organization Development Journal, 21(2), 75-83. 
Ling, Y., Simsek, Z., Lubatkin, M. H., \& Veiga, J. F. (2008). Transformational leadership's role in promoting corporate entrepreneurship: Examining the CEO-TMT interface. Academy of Management Journal, 51, 557-576.

Lubatkin, M., Simsek, Z., Ling, Y., \& Veiga, J. F. (2006). Ambidexterity and performance on small- to medium-sized firms: The pivotal role of TMT behavioral integration. Journal of Management, 32, 646-672.

Magni, M., Proserpio, L., Hoegl, M., \& Provera, B. (2009). The role of team behavioral integration and cohesion in shaping individual improvisation. Research Policy, 38, 1044-1053.

Mathieu, J., Maynard, M. T., Rapp, T., \& Gilson, L. (2008). Team effectiveness 1997-2007: A review of recent advancements and a glimpse into the future. Journal of Management, 34, 410-476.

McGrath, J. E. (1964). Social psychology: A brief introduction. New York: Holt, Rinehart and Winston.

Miller, L. K., \& Hamblin, R. L. (1963). Interdependence, differential rewarding, and productivity. American Sociological Review, 28, $768-777$.

Mohammed, S., \& Dumville, B. (2001). Team mental models in a team knowledge framework: Expanding theory and measurement across disciplinary boundaries. Journal of Organizational Behavior, 22, 89-106.

Mooney, A., \& Sonnenfeld, J. (2001). Exploring antecedents to conflict during strategic decision making: The importance of behavioral integration. Paper presented in the Academy of Management Meeting. Washington, DC: BPS Division.

Noe, R. A., Hollenbeck, J. R., Gerhart, B., \& Wright, P. M. (2000). Human resource management: Gaining a competitive advantage. New York: McGraw-Hill, Inc.

O'Reilly, C. A., Caldwell, D. F., \& Barnett, W. P. (1989). Work group demography, social integration, and turnover. Administrative Science Quarterly, 34, 21-37.

Organ, D. W. (1988). Organizational citizenship behavior: The good soldier syndrome. Lexington: Lexington Books.

Ou, A. Y., Tsui, A. S., Kinicki, A. J., Waldman, D. A., Xiao, Z., \& Song, L. J. (2014). Humble chief executive officers' connections to top management team integration and middle managers' responses. Administrative Science Quarterly, 59, 34-72.

Peters, L., \& Karren, R. J. (2009). An examination of the roles of trust and functional diversity on virtual team performance ratings. Group and Organization Management, 34, 479-504.

Podsakoff, P. M., Mackenzie, S. B., Lee, J. Y., \& Podsakoff, N. P. (2003). Common method biases in behavioural research: A critical review of the literature and recommended remedies. Journal of Applied Psychology, 88, 879-903.

Ramamoorthy, N., \& Flood, P. C. (2004). Gender and employee attitudes: The role of organizational justice perceptions. British Journal of Management, 15, 247-258.

Shea, G. P., \& Guzzo, R. A. (1987). Groups as human resources. In K. M. Rowland \& G. R. Ferris (Eds.), Research in personnel and human resources management (pp. 323-356). Greenwich: JAI Press.

Shin, S. J., \& Zhou, J. (2007). When is educational specialization heterogeneity related to creativity in research and development teams? Transformational leadership as a moderator. Journal of Applied Psychology, 92, 1709-1721.

Siegel, P. A., \& Hambrick, D. C. (1996). Business strategy and the social psychology of top management teams. In P. Shrivastava, A. Huff, \& J. Dutton (Eds.), Advances in strategic management (pp. 91-119). Greenwich: JAl Press.

Simsek, Z., Lubatkin, M., Veiga, J., \& Dino, R. (2005). Modeling the multilevel determinants of top management team behavioral integration. Academy of Management Journal, 48, 69-84.

Smith, K. G., Smith, K. A., Olian, J. D., Sims, H. P., O'Bannon, D. P., \& Scully, J. A. (1994). Top management team demography and process: The role of social integration and communication. Administrative Science Quarterly, 39, 412-438.

Somech, A., Desivilya, H. S., \& Lidogoster, H. (2008). Team conflict management and team effectiveness: The effects of task interdependence and team identification. Journal of Organizational Behavior, 30, 359-378.

Stewart, G. L., \& Barrick, M. R. (2000). Team structure and performance: Assessing the mediating role of intrateam process and the moderating role of task type. Academy of Management Journal, 43, 135-148.

Subin, l., \& Workman, J. P. (2004). Market orientation, creativity, and new product performance in high-technology firms. Journal of Marketing, 68, 114-132.

Tekleab, A. G., Karaca, A., Quigley, N. R., \& Tsang, E. W. K. (2016). Re-examining the functional diversity-performance relationship: The roles of behavioral integration, team cohesion, and team learning. Journal of Business Research, 69, 3500-3507.

Thamhain, H. J. (2003). Managing innovative R\&D teams. R\&D Management, 33, 297-311.

Thompson, J. D. (1967). Organizations in action. New York: McGraw-Hill Book Company.

Tjosvold, D., Tang, M. M. L., \& West, M. (2004). Reflexivity for team innovation in China: The contribution of goal interdependence. Group and Organization Management, 29, 540-559.

Van der Vegt, G. S., Emans, B. J. M., \& van de Vliert, E. (2000). Affective responses to intragroup interdependence and job complexity. Journal of Management, 26, 633-655.

Van der Vegt, G. S., \& Janssen, O. (2003). Joint impact of interdependence and group diversity on innovation. Journal of Management, 29, 729-751.

Van der Vegt, G. S., van de Vliert, E., \& Oosterhof, A. (2003). Informational dissimilarity and OCB: The role of intrateam interdependence and team identification. Academy of Management Journal, 46, 715-727.

Von Hippel, E. (1988). The sources of innovation. New York: Oxford University Press.

Von Hippel, E. (2005). Democratizing innovation. Cambridge: MIT Press.

Wageman, R. (1995). Interdependence and group effectiveness. Administrative Science Quarterly, 40, 145-180.

Wageman, R. (2001). How leaders foster team self-management: The relative effects of design activities and hands-on coaching. Organization Science, 12, 559-577.

Weldon, E., \& Weingart, L. (1993). Group goals and group performance. British Journal of Social Psychology, 32, 307-334.

Zellmer-Bruhn, M., \& Gibson, C. B. (2006). Team strategic context: Implications for process and performance. Academy of Management Journal, 49, 501-518.

Zhang, Y., Zeng, D., Zhang, L., \& Lu, L. Y. (2007b). R\&D team governance and R\&D performance: Empirical evidence from Chinese software enterprises. Journal of Technology Management in China, 2, 71-83.

Zhang, Z. X., Hempel, P. S., Han, Y. L., \& Tjosvold, D. (2007a). Transactive memory system links team characteristics and performance. Journal of Applied Psychology, 92, 1722-1730 